\title{
Erratum zu: Grünpatenschaften im Spannungsfeld von neoliberaler Stadtpolitik und urbanen Bürgerbewegungen
}

\author{
Miriam Gruber ${ }^{1}$ \\ Online publiziert: 18. Mai 2021 \\ (c) Der/die Autor(en) 2021
}

\section{Erratum zu:}

\section{Standort 2019}

https://doi.org/10.1007/s00548-019-00630-0

Der Artikel Grünpatenschaften im Spannungsfeld von neoliberaler Stadtpolitik und urbanen Bürgerbewegungen von Miriam Gruber wurde ursprünglich Online First ohne „Open Access“ auf der Internetplattform des Verlags publiziert. Nach der Veröffentlichung in Band 44 Heft 3 pp. 175-181 hatten sich die Autoren für eine „Open Access“Veröffentlichung entschieden. Das Urheberrecht des Artikels wurde deshalb in ( $)$ Der/die Autor(en) 2021 geändert.
Open Access Dieser Artikel ist jetzt unter der Creative Commons Namensnennung 4.0 International Lizenz veröffentlicht, welche die Nutzung, Vervielfältigung, Bearbeitung, Verbreitung und Wiedergabe in jeglichem Medium und Format erlaubt, sofern Sie den/die ursprünglichen Autor(en) und die Quelle ordnungsgemäß nennen, einen Link zur Creative Commons Lizenz beifügen und angeben, ob Änderungen vorgenommen wurden.

Die in diesem Artikel enthaltenen Bilder und sonstiges Drittmaterial unterliegen ebenfalls der genannten Creative Commons Lizenz, sofern sich aus der Abbildungslegende nichts anderes ergibt. Sofern das betreffende Material nicht unter der genannten Creative Commons Lizenz steht und die betreffende Handlung nicht nach gesetzlichen Vorschriften erlaubt ist, ist für die oben aufgeführten Weiterverwendungen des Materials die Einwilligung des jeweiligen Rechteinhabers einzuholen.

Weitere Details zur Lizenz entnehmen Sie bitte der Lizenzinformation auf http://creativecommons.org/licenses/by/4.0/deed.de.

Die Online-Version des Originalartikels ist unter https://doi.org/ 10.1007/s00548-019-00630-0 zu finden.

Miriam Gruber

miriam.gruber@uni-bonn.de

1 Geographisches Institut, Universität Bonn,

MeckenheimerAllee 166, 53115 Bonn, Deutschland 